\title{
Concentration-dependent toxicity effect of SDBS on swimming behavior of freshwater fishes
}

Ying Zhang ${ }^{{ }^{*}}$, Jing Ma ${ }^{\mathrm{a}}$, Siyun Zhou ${ }^{\mathrm{a}}$, Fang Ma ${ }^{\mathrm{b}}$ *

a Laboratory of Industrial Ecology and Environmental Engineering (MOE), School of Environmental Science and Technology, Dalian University of Technology, Dalian 116024, China

${ }^{\mathrm{b}}$ State Key Laboratory of Urban Water Resource and Environment, Harbin Institute of Technology, 73 Huanghe Road, Nan Gang District, Harbin 150090, China

*E-mail: yzhang@dlut.edu.cn (Y. Zhang); mafang@hit.edu.cn (F. Ma).

\begin{abstract}
:
Sodium dodecyl benzene sulfonate (SDBS) is a kind of widely used anionic surfactant and its discharge may pose potential risk to the receiving aquatic ecosystem. The aim of our study is to investigate the toxic effect of SDBS on fish swimming behavior quantitatively, followed by examination whether there are significant differences of swimming behavior among applied fish species (i.e. zebra fish (Danio rerio), Japanese medaka (Oryzias latipes) and red carp (Cyprinus carpio)). The swimming speed and vertical position were analysed after the fish exposed to SDBS aiming to reflect the toxicity of SDBS on fish. Our results showed that the swimming behavior of three fishes was significantly affected by SDBS, although there were slight differences of swimming pattern changes among three fish species when they exposed to the same concentration of SDBS. It could be seen that red carp, one of the native fish species in China, can be used as a model fish to reflect the water quality changes as well as zebra fish and Japanese medaka which are commonly used as model fishes. Our study also illustrated that the swimming behavior monitoring may have a good application prospect in pre-warning of water quality.
\end{abstract}

Keywords: sodium dodecyl benzene sulfonate (SDBS); biomonitoring; zebra fish; red carp; Japanese medaka; entropy 


\section{Introduction}

Sodium dodecyl benzene sulfonate (SDBS), a kind of anionic surfactant, is widely used in chemical and biochemical industries due to its low cost and good performance (Dubey and Pal, 2012). The production of SDBS accounts for nearly $90 \%$ of the total amount of synthetic detergents in China (Wang et al., 2006). The major pathway of SDBS entering the environment is the relevant wastewater discharge. SDBS can be microbial degraded within 6 to 22 days (Schleheck et al., 2000), and the conventional wastewater treatment plants are relatively inefficient in SDBS removal (Ivankovic and Hrenovic, 2010), with a result of SDBS detection in the natural water environment ( $\mathrm{Wu}$ and $\mathrm{Li}, 2002$ ). Therefore, the occurrence of SDBS in water environment may pose toxic effect on aquatic organisms.

The toxic effect of SDBS has captured more and more attentions. Wu et al. (2006) investigated the response of fish (Lateolabrax japonicas) to the toxicity of SDBS, whose results showed that the enzymatic activity of catalase (CAT), glutathione peroxidase (GPx) and brain acetyl cholinesterase (AChE) were influenced by SDBS. Yu et al. (2008) used hybrid tilapia $\left(\right.$ Rilapianilotica $\odot \times T$. aurea ${ }^{\Im}$ ) to study the immune-toxicity of SDBS and found that its immunity function was inhibited while the exposure concentration was higher than $0.40 \mathrm{mg} / \mathrm{L}$.

In order to investigate the toxic effects of chemical pollutants on aquatic organisms, biological monitoring has been regarded as an effective tool to provide more fruitful and virtual bio-toxicity data for the following risk assessment. For example, Reyhanian et al. (2011) analyzed the toxic effects of ethinyl estradiol on behavior of adult male zebra fish (Danio rerio) and found that ethinyl estradiol altered the behavior significantly that the fish tended to spend a lot of time at the surface when exposed to the concentration of $25 \mathrm{ng} / \mathrm{L}$. Robinson et al. (2013) examined the behavior of adult zebra fish (Danio rerio) exposed to kynurenic acid for $20 \mathrm{~min}$ and found that the latency of fish decreased, the number of top entries increased and the fish tended to stay at the top of tank. Nwani et al. (2013) found the herbicide fish (Tilapia zillii) presented uncoordinated behavior (such as erratic and jerky swimming, tendency to jump out of water, frequent surfacing and gulping of air) when exposed to the test solutions with higher concentration. All these studies illustrated that a bio-monitoring system with fish as test organism can be applied as a useful tool to reflect the toxic effect of contaminants. 
Behavioral toxicology is a new field to study chemical toxicants and their influence on brain function. Chemicals can affect the brain and that the earliest expression of toxicity could be found in altered behavior, thinking, or mood (Needleman, 1995). Behavioral toxicologists make important contributions in risk assessment for the foreseeable future by implementing studies in animals designed to address basic risk assessment issues, including studies of dose-effect relationships, susceptibility and extrapolation. However, the scientific community has until recently paid little systematic attention to the impact of toxicants on behavior (Bushnell et al., 2010).

Behavior monitoring, one of the typical biological monitoring tools that commonly used, can be developed as a real-time monitoring tool to provide continuous information on in situ environmental changes (e.g. water quality). For example, Kang et al. (2009a) investigated the toxic effect of some chemicals on three fishes (Oryzias latipes, Poecilia reticulate and Gobiocypris rarus) by monitoring their swimming behavior and found that the swimming speed and the position of three fish species were significantly affected by test chemicals, although the changes of behavioral patterns were different among these test fish species and the toxic chemicals. Thiem et al. (2010) conducted a study on the short-term activity of fishes (rainbow trout and Murray river crayfish) by simultaneous video monitoring, and concluded that the variation of radio-signal strength was a valid method in biotoxicity monitoring. Gerhardt et al. (2004) investigated the toxicity of acid mine drainage on the local mosquito fish (Gambusia holbrooki Girard) and the shrimp (Atyaephyra desmaresti Millet) by on-line behavioral toxicity bioassay, and found that the local fish was more sensitive to acid mine drainage than the shrimp. It can be seen that the biological behavior changes of aquatic organisms can be used to study the eco-toxicological effect of environmental changes. Since fish is an ideal test organism for investigating the toxicity of chemicals in water (Little and Finger, 1990), a variety of model fish were listed in the bio-toxicity test, e.g. zebra fish (AFNOR, 1998; ISO, 1996; JISC, 2000), Japanese medaka (AQSIQ, 2013; EPA, 1991; OECD210, 1992), rainbow trout (ASTM, 2007; BSI, 1995) and fathead minnow (ASTM, 2007; BSI, 1995). The performances of fish in bio-toxicity test may depend on the test condition and local conditions of water environment. In China, there are several kinds of native fish species mentioned in the water and wastewater toxicity test, e.g. carp (Cyprinus carpio) (AQSIQ, 2008a), Gobiocypris rarus (AQSIQ, 2008b) and Carassius auratus (AQSIQ, 2008b). 
However, there was no study on behavior monitoring using Chinese native fish species for bio-toxicity test.

In our study, the toxic effect of SDBS on aquatic organism was investigated by investigation on the swimming behavior of three selected small freshwater fishes using 3D-biosensor. The fishes used as tested organisms were zebra fish (Danio rerio), Japanese medaka (Oryzias latipes) and red carp (Cyprinus carpio). The swimming speed and vertical position were monitored by two cameras set in the 3D-biosensor and recorded on real-time when the test fish exposed to SDBS. The change of swimming behavior was analysed quantitatively to reflect the toxic effect of SDBS. Here, red carp was chosen as the typical native species in China, while Japanese medaka and zebra fish were used as the representatives of international model fishes. The aim of our short-term toxicity test is to illustrate whether SDBS has toxic effect on fish swimming behavior, as well as to investigate whether there are significant differences in swimming behavior among these three fishes.

\section{Materials and methods}

\subsection{Test chemical and test fishes}

Sodium dodecyl benzene sulfonate (SDBS, $>90 \%$ purity) were imported from Germany company and retailed in China. Zebra fish (mean \pm standard deviation of length, $35 \pm 5 \mathrm{~mm}$; weight $0.25 \pm 0.1 \mathrm{~g}$ ) and red carp (length $40 \pm 5 \mathrm{~mm}$; weight $0.85 \pm 0.1 \mathrm{~g}$ ) were purchased from a professional fish shop (Yule pet market, Dalian, China). Japanese medaka were hatched and bred in our laboratory to adult, with length of $35 \pm 5 \mathrm{~mm}$ and weight of $0.25 \pm 0.1 \mathrm{~g}$. Before exposure, all fishes were kept at $22 \pm 1^{\circ} \mathrm{C}$ under a photoperiod of 14:10 hr (light: dark) and were fed twice daily. Japanese medaka was fed with artemia nauplii (newly hatched $\leq 24 \mathrm{hr}$ old); zebra fish was fed with nematode (Dandong, Liaoning, China); and red carp was fed with fish meal (Leader, Inc., Beijing, China).

\subsection{Exposure test}

The exposure test was conducted as mentioned in Kang et al. (2009a). SDBS concentrations were set to be $2 \mathrm{mg} / \mathrm{L}, 10 \mathrm{mg} / \mathrm{L}, 20 \mathrm{mg} / \mathrm{L}, 25 \mathrm{mg} / \mathrm{L}$ and $50 \mathrm{mg} / \mathrm{L}$ according to the $\mathrm{LC} 50$ value of SDBS, $20 \mathrm{mg} / \mathrm{L}$. Any individual fish for test was exposed to a certain concentration of SDBS 
solution for $60 \mathrm{~min}$ after pre-exposed for $30 \mathrm{~min}$ with dechlorinated tap water. The toxicity test of each concentration of SDBS was repeated 8 times.

The schematic of biological monitoring equipment was shown as Fig.1, which was friendly supplied by Seiko Electric Co., Ltd., Fukuoka, Japan. For each exposure test, a selected fish was placed into a flow-through test chamber $\left(10 \times 10 \times 15 \mathrm{~cm}^{3}\right)$ with $1.5 \mathrm{~L}$ test solution. The dechlorinated tap water and test solution were delivered to the test chamber by pump (Longerpump BT300-2J, Baoding, China) with a continuous flow (flow rate $400 \mathrm{~mm}^{3} / \mathrm{s}$ ). The behavior of test fish was recorded 3 times per second continuously during the total 90 minutes exposure period and then quantified with the recorded three dimensional (3D) data, $x, y, z$ coordinates.

\subsection{Data and Statistical analysis}

The characterizations of swimming behavior were expressed with the following parameters:

(1) Motion trail: expressed as the relationship between swimming speed (SPD, $\mathrm{mm} / \mathrm{s}$ ) and vertical position $(\mathrm{Y}, \mathrm{mm})$. The range of swimming speed (SPD, $\mathrm{mm} / \mathrm{s}$ ) was divided as the followings: $0 \leq S P D_{1} \leq 20,20 \leq S P D_{2} \leq 40,40 \leq S P D_{3} \leq 60,60 \leq S P D_{4} \leq 80$ and $S P D_{5} \geq 80$. The vertical position (Y, mm) was analysed in the categories as: $0 \leq Y_{1} \leq 20,20 \leq Y_{2} \leq 40,40 \leq Y_{3} \leq 60$, $60 \leq Y_{4} \leq 80$, and $80 \leq Y_{5} \leq 100$. If $Y=0$, it means the fish stays at the water surface.

(2) Swimming speed: expressed as $\Delta V$, where $\Delta V=V_{\text {exposed }}-V_{\text {control. If }} \Delta V>0$, it means the swimming speed become higher after exposure, and vice versa.

(3) Surface behavior: expressed as $\Delta$ retention time of surface behaviour, where $\Delta$ Retention time $=$ Retention time exposed $^{-}$Retention time control ,if $\Delta$ Retention time $>0$, it means the retention time of surface behavior is longer than that of the control fish and it was considered that the fish tended to stay in the surface of water due to the toxic effects of solution.

(4) Shannon-Weaver entropy: calculated as formula (1) presented in Fukuda et al. (2010),

$$
\text { Entropy }=-\frac{1}{\log _{2} n} \sum_{i=1}^{n} p_{i} \log _{2} p_{i}(i=1,2, \ldots, n)
$$

where: $n=$ the number of categories assigned to the parameter;

$P_{i}=$ the proportional frequency of the parameters in category $i$. 
The entropy value is used to evaluate the uniformity of the parameters. Entropy ranged from 0 to 1 , where 1 indicates that the data are distributed uniformly across all of the five categories divided, and 0 indicates that all data are assigned to a single category.

One-way ANOVA was used to check the differences $(p<0.05)$ in the retention time and swimming speed under exposure to SDBS of different concentrations by software SPSS 20.0. The data in this study, if without specialization, were expressed as mean \pm SD. Here, all of the parameters were retrieved from the raw records by 3D-biomonitor and analyzed at consecutive 10 min interval.

\section{Results}

\subsection{Motion trail}

The swimming behavior was expressed by the relationship between swimming speed and vertical position (Fig.2). Here, the concentration of SDBS $50 \mathrm{mg} / \mathrm{L}$ was shown, only, as an example.

The common swimming pattern (under control condition) of three fish species were shown in Fig.2 (I-A), Fig.2 (II-A) and Fig.2 (III-A). It can be seen that zebra fish preferred swimming across the whole test chamber, red carp tended to stay in the upper layer of the test chamber, while Japanese medaka tended to stay in the lower layer of the test chamber. The red carp was lower in respect of swimming speed and it tended to stay in the upper layer, which may be due to its bigger body and more oxygen requirement.

When exposed to SDBS of $50 \mathrm{mg} / \mathrm{L}$, the swimming speed and vertical position of zebra fish were observed to be different from that under control condition in the first 30 minutes (Fig.2 (I)), which were same for red carp (Fig.2(II)) and Japanese medaka (Fig.2 (III)). In detail, the behavior change of three fish species could be easily observed by their decrement in swimming speed after the first 10 minutes exposure, as well as by their preference of staying in the upper layer of water face.

\subsection{Swimming speed}

When exposed to different concentrations of SDBS, the changes of swimming speed $(\Delta V)$ for zebra fish, red carp and Japanese medaka were shown in Fig.3. 
For zebra fish (Fig.3 (I)), the peak of $\Delta V$ kept at $\pm 5 \mathrm{~mm} / \mathrm{s}$ when exposed to SDBS from 2 $\mathrm{mg} / \mathrm{L}$ to $10 \mathrm{mg} / \mathrm{L}$, which illustrated there were no significant changes of swimming speed. At the exposure time of 41-50 min, the peak of $\Delta V$ shifted to left when exposed to SDBS of $50 \mathrm{mg} / \mathrm{L}$, which suggested that the mean value of swimming speed decreased. While at the exposure time of 51-90 min, all the peaks of $\Delta V$ shifted to the left with the increment of SDBS concentration in the range of 20 and $50 \mathrm{mg} / \mathrm{L}$. It can be concluded that there were no significant changes in swimming speed of zebra fish when it exposed to SDBS of 2 and $10 \mathrm{mg} / \mathrm{L}$; while exposed to SDBS of 20 and $50 \mathrm{mg} / \mathrm{L}$, the swimming speed decreased, and the abnormal behavior (the peak of $\Delta V> \pm 5 \mathrm{~mm} / \mathrm{s}$ ) appeared earlier with the increment of SDBS concentration.

For red carp (Fig.3 (II)), the peak of $\Delta V$ kept at $\pm 5 \mathrm{~mm} / \mathrm{s}$ at the concentration of SDBS from $2 \mathrm{mg} / \mathrm{L}$ to $25 \mathrm{mg} / \mathrm{L}$, which showed there were no significant changes of swimming speed; the peak of $\Delta V$ did not shift to the left until exposed to SDBS of $50 \mathrm{mg} / \mathrm{L}$ for $40 \mathrm{~min}$, which illustrated that the speed of red carp decreased with the increment of SDBS concentration.

For Japanese medaka (Fig.3 (III)), the peak of $\Delta V$ kept at $\pm 5 \mathrm{~mm} / \mathrm{s}$ when exposed to SDBS from $2 \mathrm{mg} / \mathrm{L}$ to $20 \mathrm{mg} / \mathrm{L}$, which showed there were no significant changes of swimming speed; the peak of $\Delta V$ shifted to the left when exposed to SDBS of $25 \mathrm{mg} / \mathrm{L}$ for $41 \mathrm{~min}$, or the peak of $\Delta V$ shifted to the left when exposed to SDBS of $50 \mathrm{mg} / \mathrm{L}$ for $31 \mathrm{~min}$. It was known that the swimming speed of Japanese medaka exposed to SDBS of 2-20 mg/L did not change obviously, and when it exposed to SDBS of $25-50 \mathrm{mg} / \mathrm{L}$, the speed would decrease. Besides, the changes of swimming speed reached to the peak earlier when the concentrations of SDBS increased.

\subsection{Surface behavior}

Frequency of surface behavior can be used as a quantitative index to evaluate the toxicity on fish behavior. The retention time of surface was used to evaluate the surface behavior.

Under control condition, all of the three fishes were swimming across the vertical position (Fig.2 (I-A, II-A and III-A)); therefore there were no significant changes of the retention time for the whole 90 min (Fig.4 (I)).

Under exposure conditions, the $\triangle$ retention time (difference value of retention time after and before exposure) of surface behavior increased with the increment of SDBS concentration for three fish species (Fig.4). There were no significant changes in swimming pattern for all three 
fishes at SDBS of $2 \mathrm{mg} / \mathrm{L}$; while exposed to SDBS of $10 \mathrm{mg} / \mathrm{L}$, the $\Delta$ retention time of zebra fish increased in the first $30 \mathrm{~min}$ and then decreased, however there were no significant changes in swimming pattern for the other two fishes. When exposed to SDBS of 25 and $50 \mathrm{mg} / \mathrm{L}$, the $\Delta$ retention time of surface behavior for all three fishes increased, reflecting the fish tended to stay near the water surface. Kang et al. (2009b) observed an increment of the time that fish stay near the water surface of Japanese medaka after exposed to potassium cyanide, fenitrothion or benthiocarb, which showed that surface behavior would be significant when the fish exposed to the toxicants at high level (Little and Finger, 1990). In our study, the retention time of surface behavior increased with SDBS concentrations for all test fish species. It suggested that the surface behavior can be used to evaluate the bio-toxicity of wastewater.

\subsection{Entropy}

The entropy of swimming speed (Fig.5) and vertical position (Fig.6) were used to characterize the behavioral responses of the test fish to SDBS at different concentrations. The entropy values range from 0 to 1 , where the value of 1 indicates that the data are distributed uniformly across the categories, and 0 indicates that all data are assigned to be the same category. That is to say, fish is under normal condition if the entropy is close to 1 , and vice versa.

Temporal changes in the entropy of swimming speed under SDBS exposure were shown in Fig.5. Under control condition (Fig.5 (A)), the entropy of all three fishes were about 0.6, therefore the distribution of swimming speed were similar. When exposed to SDBS of $10 \mathrm{mg} / \mathrm{L}$ (Fig.5 (C)), the entropy of zebra fish decreased at exposure time of $51 \mathrm{~min}$, while there seemed no changes for the other two fishes; when exposed to SDBS of $20 \mathrm{mg} / \mathrm{L}$ (Fig.5 (D)), the entropy of zebra fish and red carp decreased; when exposed to SDBS of 25 and $50 \mathrm{mg} / \mathrm{L} \mathrm{(Fig.5} \mathrm{(E)} \mathrm{and} \mathrm{(F)),} \mathrm{the} \mathrm{entropy} \mathrm{of}$ all three changed significantly. From Fig.5 (F), it can be seen that at SDBS of $50 \mathrm{mg} / \mathrm{L}$, the changes of entropy for zebra fish and red carp were similar, i.e. the entropies increased at 31-40 min and then decreased significantly from $41 \mathrm{~min}$; the entropy of Japanese medaka decreased directly after exposure, this tendency became clearly at 41-50 min.

Temporal changes in the entropy of vertical position under exposure to SDBS were shown in Fig.6. Under control condition (Fig.6 (A)), the entropies of vertical position for both were kept at 0.9 , and that of was about 0.8 . It can be concluded that the vertical swimming range of was 
narrower than that of the other two fishes. When the fish exposed to different concentrations of SDBS ranged from $10 \mathrm{mg} / \mathrm{L}$ to $50 \mathrm{mg} / \mathrm{L}$, the entropy decreased for zebra fish (at $50 \mathrm{~min}$ ) (Fig.6 (I)) was earlier than that for red carp (at $60 \mathrm{~min}$ ) (Fig.6 (II)); while the entropy for Japanese medaka decreased only when it exposed to SDBS of 25 and $50 \mathrm{mg} / \mathrm{L}$ (Fig.6 (III-E, III-F)).

\section{Discussions}

Fish behaviors include crowd, phototaxis, predation and swimming behavior. Here, our study only focused on the behavior of aquatic organisms after stimulated, and pays no attention to the physiological process such as feel, nervous system and muscle.

Biological behavior monitoring, as a well-established method, can be used to evaluate the toxicity of pollution instead of $\mathrm{EC}_{50}$ of lux bacteria or $\mathrm{LC}_{50}$ of fish. Exposed to linear alkylbenzene sulfonate (LAS), the 30 min $\mathrm{EC}_{50}$ (Luminescence inhibition) of Vibrio fischeri was $109.7 \mathrm{mg} / \mathrm{L}$ (Sutterlin et al., 2008), which was much higher than the highest concentration of our study. It might suggest that toxicants can be detected earlier by monitoring swimming behavior of fish, i.e. the behavior monitoring may be a practical index to qualify the toxicity of chemical toxicants. In this study, abnormal behavior can be detected when zebra fish exposed to SDBS of $10 \mathrm{mg} / \mathrm{L}$ within $1.5 \mathrm{~h}$ monitoring, the behavior of all three fishes showed significantly differences under SDBS of $25 \mathrm{mg} / \mathrm{L}$; in addition, the abnormal behaviors expressed as mentioned above were occurred more and more significantly and quickly when the concentration of SDBS increased. Therefore, it can be expected that swimming behavior can be used to reflect the bio-toxicity of wastewater, and it will have a good application prospect in real time monitoring and pre-warning of the water quality.

The toxicity of SDBS was illustrated by monitoring swimming behavior in our study. The changes of fish swimming behavior were expressed from four indexes we applied, i.e. the fish swimming trail, swimming speed, surface behavior and Shannon-Weaver entropy. The exposure of three fishes to SDBS of $50 \mathrm{mg} / \mathrm{L}$ did affect their swimming behavior; meanwhile the trends of three fish species swimming behavior changes seemed similarly. That suggested that Chinese native fishes, red carp can be used as test fish in the bio-monitoring system.

As to the sensitivity of these three fished we used, it seemed slightly different from the different index of swimming behavior. According to the swimming speed, zebra fish presented the 
higher sensitivity to the toxic effect of SDBS than that of Japanese medaka or red carp. According to the $\Delta$ retention time of surface behavior, the toxicity of SDBS on three fishes was illustrated to be in the order of zebra fish > Japanese medaka > red carp. According to the entropy of swimming speed, the changes of swimming speed for three fishes to SDBS listed as: zebra fish > red carp > Japanese medaka. According to the entropy of vertical position, the changes of vertical position for three fishes to SDBS was ranked as, zebra fish > red carp > Japanese medaka, which is the same as that of swimming speed. It can be concluded that zebra fish was considered to be the most sensitive fish to the toxicity of SDBS, while the sensitivities of the other two fishes were similar. That suggested that Chinese native fish, red carp, was not the best choice, compared with zebra fish and Japanese medaka, for real-time monitoring of water quality in China.

Considering the swimming pattern of Japanese medaka when exposed to SDBS, our results showed a little difference in swimming speed compared with other two fish species. According to the previous results conducted (Kang et al., 2009a), the activity range (swimming range in the test chamber) of Japanese medaka reduced immediately after exposure to SDBS of $12.5 \mathrm{mg} / \mathrm{L}$, and some Japanese medaka performed abnormally in the surface behavior (the retention time of surface behavior under $20 \mathrm{~mm}$ vertical position $>15 \mathrm{~s})$ and high speed swimming (> $250 \mathrm{~mm} / \mathrm{s})$ when the concentration increased, some fish even died after exposure to SDBS of $20 \mathrm{mg} / \mathrm{L}$ for 71-80 min. But in our study, there was no abnormal behavior occurred under the concentration of SDBS from $2 \mathrm{mg} / \mathrm{L}$ to $50 \mathrm{mg} / \mathrm{L}$. These differences may be, partially, contributed to the different characterizations of water quality used for culturing in Japan and China.

The fish species used in this study were prospected to have a good application in pre-warning of the water quality. The results of our study may be site-specific, which illustrated the toxicity effect of SDBS under local water environment on the locally cultured model fish. Further studies need to be conducted for more chemical contaminants or wastewater samples. However, this study gave an example of how to make sure whether the native fish species should be applied in toxicity monitoring.

\section{Conclusions}

In this study, the toxicity of a typical pollutant SDBS was investigated with fish swimming behavior monitoring. From the results, it can be concluded: 
(1) The monitoring of fish swimming behavior can be used to evaluate the toxicity level and severity level of pollution accident, and it will have a good application prospect in real time monitoring and pre-warning of the water quality.

(2) The sensitivity of fish species to SDBS may be different when different swimming behavior parameters were used; the changes of swimming behavior of zebra fish under exposure to SDBS were more obvious than other two fish species.

(3) Red carp, a native fish species in China, was suitable to be used in monitoring the water quality changes, but not the best choice for real-time monitoring of water quality.

\section{Acknowledgements}

Thanks should be firstly given to the National Natural Science Foundation of China (NSFC-JST 21261140334) and National Key Scientific and Technology Project for Water Pollution Treatment of China (2012ZX07202-006). Thanks also go to Seiko Electric Co. Ltd. (Japan) for friendly provision of the lab-mode 3D-biosensor.

\section{References}

AFNOR, 1998. Association Francaise de Normalisation, Determination of the acute lethal toxicity of substances to a freshwater fish (Brachydanio rerio Hamilton-Buchanan (Teleostei, Cyprinidae)) (NF T90-303).

AQSIQ, 2008a. Administration of Quality Supervision, Inspection and Qurantine of the People's Republic of China, Chemicals-Bioconcentration-Flow-through fish test (GB/T 21800-2008).

AQSIQ, 2008b. Administration of Quality Supervision, Inspection and Qurantine of the People's Republic of China, Chemicals-Fish, short-term toxicity test on embryo and sac-fry stages (GB/T 21807-2008).

AQSIQ, 2013. Administration of Quality Supervision, Inspection and Qurantine of the People's Republic of China, Chemicals-Fish (Oryzias latipes, d-rR Medaka) early life stage toxicity test (GB/T 29764-2013).

ASTM, 2007. American Society for Testing Matierials, Standard guide for conducting acute toxicity tests on test materials with fishes, macroinvertebrates, and amphibians (ASTM E729-1996).

BSI, 1995. British Standards Institution, Determination of the prolonged toxicity of substances to freshwater fish - Method for evaluating the effects of substances on the growth rate of rainbow trout [Oncorhynchus mykiss Walbaum (Teleostei, Salmonidae)] (BS 6068-5.17).

Bushnell, P.J., Kavlock, R.J., Crofton, K.M., Weiss, B., Rice, D.C., 2010. Behavioral toxicology in the 21st century: challenges and opportunities for behavioral scientists. Summary of a symposium presented at the annual meeting of the neurobehavioral teratology society, June, 2009. Neurotoxicol. Teratol. 32, 313-328.

Dubey, N., Pal, A., 2012. Micellar solubilization of octan-1-ol in aqueous solutions of SDBS and TTAB. J. Mol. Liq. 172, 12-19. 
EPA, 1991. Guidelines for conducting early life stage toxicity tests with Japanese Medaka (Oryzias Latipes), EPA report EPA/600/3-9-063, Dec.1991, EPA, Duluth.

Fukuda S, Kang IJ, Moroishi J, Nakamura A. 2010. The application of entropy for detecting behavioral responses in Japanese medaka (oryzias latipes) exposed to different toxicants. Environ Toxicol 25(5):446-55.

Gerhardt, A., de Bisthoven, L.J., Soares, A.M.V.M., 2004. Macroinvertebrate response to acid mine drainage: community metrics and on-line behavioural toxicity bioassay. Environ. Pollut. 130, 263-274.

ISO, 1996. Determination of the acute lethal toxicity of substances to a freshwater fish [Brachydanio rerio Hamilton-Buchanan (Teleostei, Cyprinidae)] (ISO 7346).

Ivankovic, T., Hrenovic, J., 2010. Surfactants in the Environment. Arh. Hig. Rada. Toksiko. 61, 95-110.

JISC, 2000. Japanese Industrial Standards Committee, Determination of the acute lethal toxicity of substances to a freshwater fish [Brachydanio rerio Hamilton-Buchanan (teleostei, Cyprinidae)] (JIS K0420-71).

Kang, I.J., Moroishi, J., Nakamura, A., Nagafuchi, K., Kim, S.G., Oshima, Y., 2009a. Biological monitoring for detection of toxic chemicals in water by the swimming behavior of small freshwater fish. J. Fac. Agric. Kyushu Univ. 54, 209-214.

Kang, I.J., Moroishi, J., Yamasuga, M., Kim, S.G., Oshima, Y., 2009b. Swimming behavioral toxicity in JapaneseMedaka (Oryzias latipes) exposed to various chemicals for biological monitoring of water quality, Atmospheric and Biological Environmental Monitoring. Springer, pp. 285-293.

Little, E.E., Finger, S.E., 1990. Swimming behavior as an indicator of sublethal toxicity in fish. Environ. Toxicol. Chem. 9, 13-19.

Needleman, H.L., 1995. Behavioral toxicology. Environ. Health Perspect. 103, 77-79.

Nwani, C.D., Ibiam, U.A., Ibiam, O.U., Nworie, O., Onyishi, G., Atama, C., 2013. Investigation on acute toxicity and behavioral changes in Tilapia zillii due to glyphosate-based herbicide, forceup. J. Anim. Plant Sci. $23,888-892$.

OECD, 1992. The Organisation for Economic Co-operation and Development, Guideline for testing of chemicals. Fish, early-life stage toxicity test (OECD210).

Reyhanian, N., Volkova, K., Hallgren, S., Bollner, T., Olsson, P.E., Olsen, H., Hallstrom, I.P., 2011. 17 alpha-Ethinyl estradiol affects anxiety and shoaling behavior in adult male zebra fish (Danio rerio). Aquat. Toxicol. 105, 41-48.

Robinson, K.S.L., Stewart, A.M., Cachat, J., Landsman, S., Gebhardt, M., Kalueff, A.V., 2013. Psychopharmacological effects of acute exposure to kynurenic acid (KYNA) in zebrafish. Pharmacol. Biochem. Behav. 108, 54-60.

Schleheck, D., Dong, W.B., Denger, K., Heinzle, E., Cook, A.M., 2000. An alpha-proteobacterium converts linear alkylbenzenesulfonate surfactants into sulfophenylcarboxylates and linear alkyldiphenyletherdisulfonate surfactants into sulfodiphenylethercarboxylates. Appl. Environ. Microbiol. 66, 1911-1916.

Sutterlin, H., Alexy, R., Kummerer, K., 2008. The toxicity of the quaternary ammonium compound benzalkonium chloride alone and in mixtures with other anionic compounds to bacteria in test systems with Vibrio fischeri and Pseudomonas putida. Ecotox. Environ. Safe. 71, 498-505. 
Thiem, J.D., Ebner, B.C., Clear, R.C., 2010. Validating variation in radio-signal strength as an index of aquatic fauna activity. Aust. J. Zool. 58, 50-55.

Wang, J., Pan, Z.J., Zhang, X.D., Wen, F.Y., Ma, T., Jiang, Y.F., Sun, W., 2006. Investigation on sonocatalytic degradation of sodium dodecylbenzenesulfonate (SDBS) in the presence of ordinary anatase $\mathrm{TiO}_{2}$. Res. Environ. Sci. 19, 81-87.

Wu, J.F., Yu, Z.M., Song, X.X., Wang, Y., 2006. Response of integrated biomarkers of fish (Lateolabrax japonicus) exposed to benzo[a]pyrene and sodium dodecylbenzene sulfonate. Ecotox. Environ. Safe. 65, 230-236.

Wu, M.Y., Li, K.B., 2002. Advances in research on treatment of surfactant pollution. Chinese Journal of Nature. 24, 138-141 (Chinese).

Yu, T.J., Jian, J.C., Lin, X., Jian, H.J., Huang, Y.V., 2008. Studies on immuntoxicity of phenol and SDBS to hybrid tilapia (Tilapia nilotica $\times$ T.aurea). South China Fisheries Science. 4, 33-37 (Chinese). 
Fig.1. Schematic of biological monitoring equipment

Fig.2. Relationship between vertical position and swimming speed at $10 \mathrm{~min}$ interval $(\mathrm{SDBS}=50 \mathrm{mg} / \mathrm{L}$ )

(A) Control condition; (B)-(E) four replicates of fish; (I) zebra fish, (II) red carp, (III) Japanese medaka, Each test was conducted with the first 30 minutes under control condition and the following 60 minutes under SDBS solution.

Fig.3. Distribution of changes of speed for three fishes during 10-min intervals under exposure to SDBS ( $n=8$ )

Fig.4. $\Delta$ Retention time of surface behavior

(i) Control, (ii) SDBS of $2 \mathrm{mg} / \mathrm{L}$, (iii) SDBS of $10 \mathrm{mg} / \mathrm{L}$, (iv) SDBS of $20 \mathrm{mg} / \mathrm{L}$, (v) SDBS of $25 \mathrm{mg} / \mathrm{L}$, (vi) SDBS of $50 \mathrm{mg} / \mathrm{L}$

Note: Data expressed as mean \pm SE $(n=8)$.

Fig.5. Temporal changes in the entropy of swimming speed during each 10-min interval (I) zebra fish, (II) red carp, (III) Japanese medaka; (A) Control condition, (B) SDBS of $2 \mathrm{mg} / \mathrm{L}$, (C) SDBS of 10 $\mathrm{mg} / \mathrm{L}$, (D) SDBS of $20 \mathrm{mg} / \mathrm{L}$, (E) SDBS of $25 \mathrm{mg} / \mathrm{L}$, (F) SDBS of $50 \mathrm{mg} / \mathrm{L}$; test continues for 90 min while the first 30 min was under control condition and 30-90 min was under exposed condition.

Fig.6. Temporal changes in the entropy of vertical position during each 10-min interval (I) zebra fish, (II) red carp, (III) Japanese medaka; (A) Control condition, (B) SDBS of 2 mg/L, (C) SDBS of 10 $\mathrm{mg} / \mathrm{L}$, (D) SDBS of $20 \mathrm{mg} / \mathrm{L}$, (E) SDBS of $25 \mathrm{mg} / \mathrm{L}$, (F) SDBS of $50 \mathrm{mg} / \mathrm{L}$; test continues for 90 min while the first 30 min was under control condition and 30-90 min was under exposed condition. 


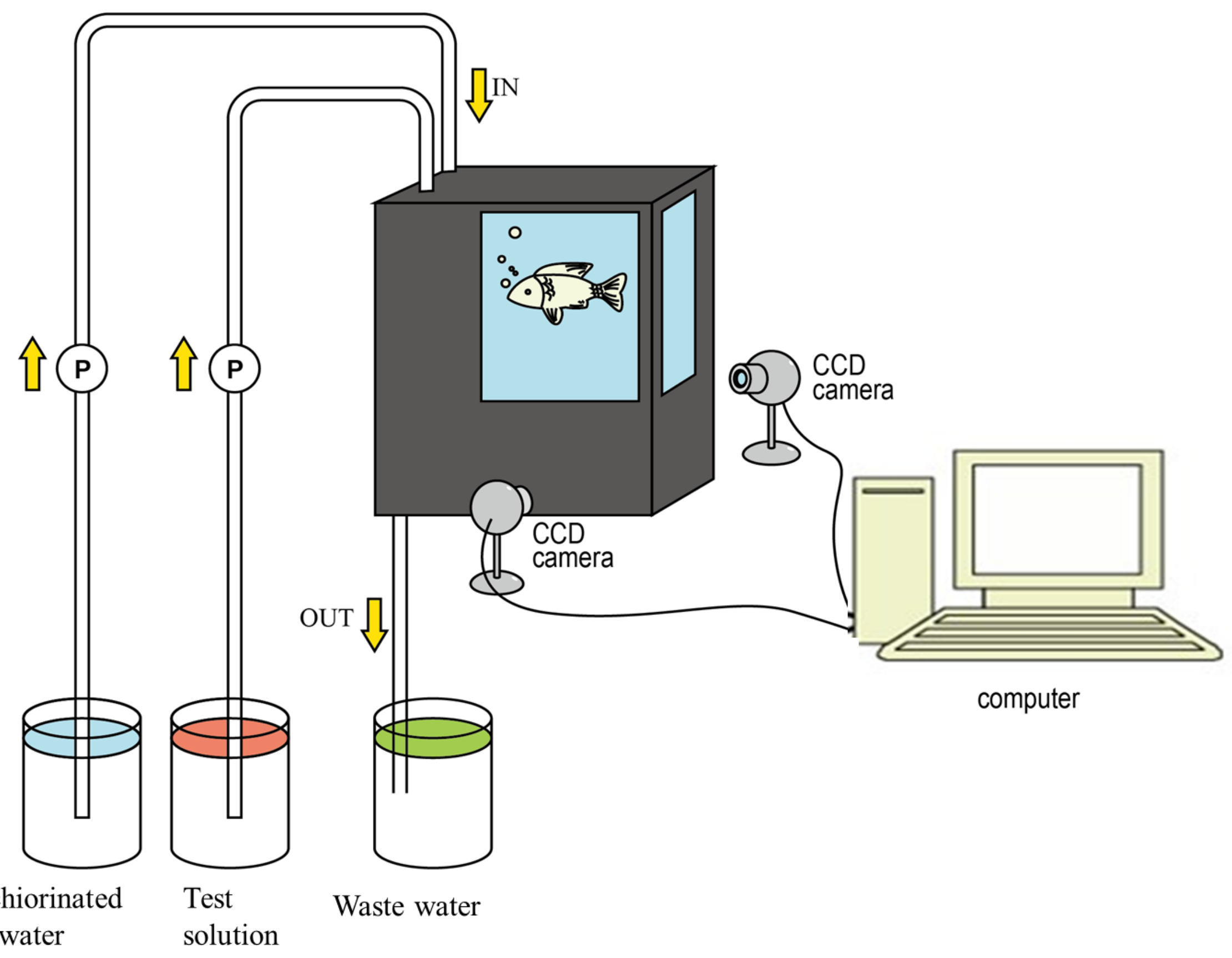

tap water solution 


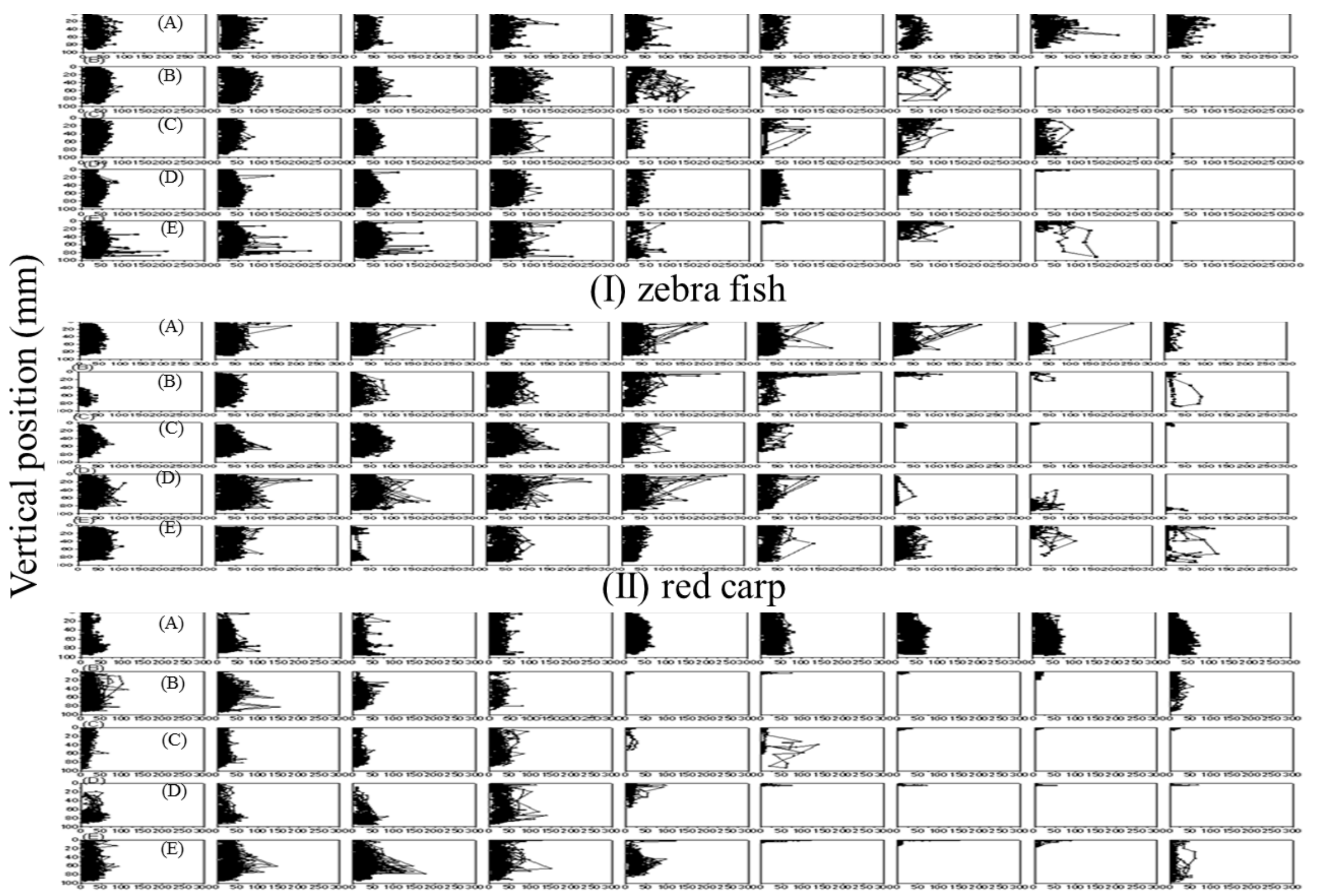

(III) Japanese medaka

0-10 $\min \quad 11-20 \mathrm{~min} \quad 21-30 \mathrm{~min}$ 31-40 $\mathrm{min} \quad 41-50 \mathrm{~min}$ 51-60 $\mathrm{min}$ 61-70 $\mathrm{min} \quad 71-80 \mathrm{~min} 81-90 \mathrm{~min}$ Swimming speed $(\mathrm{mm} / \mathrm{s})$ 

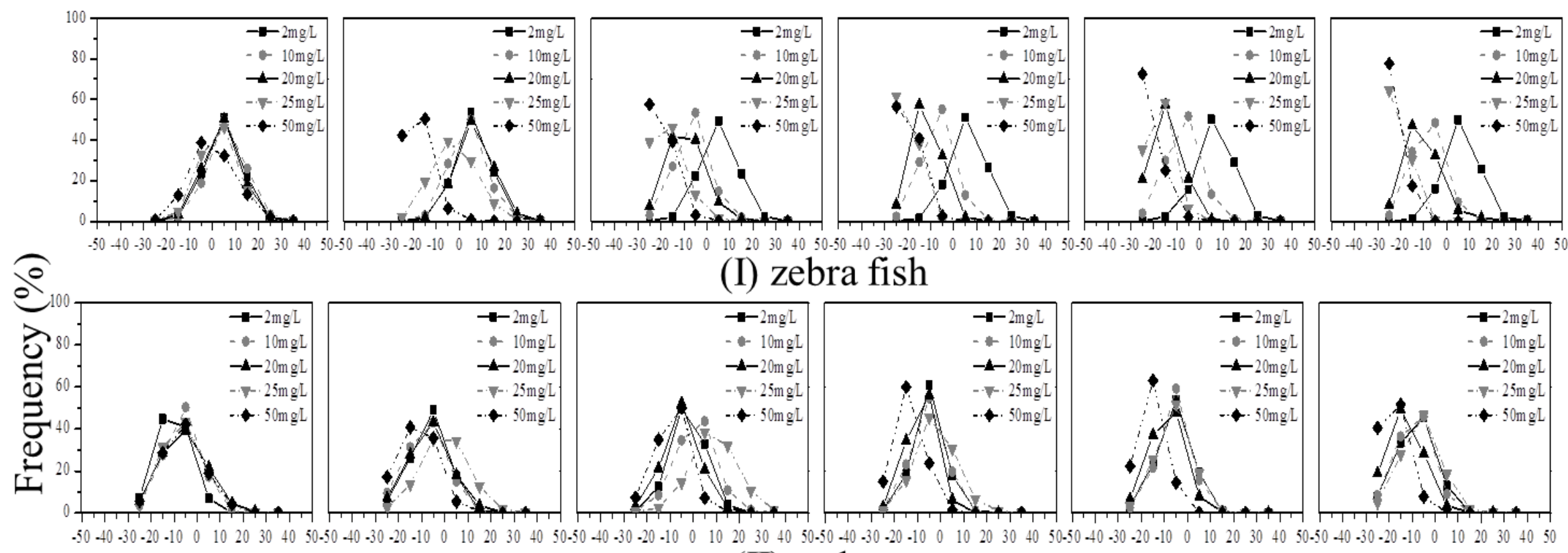

(I) zebra fish
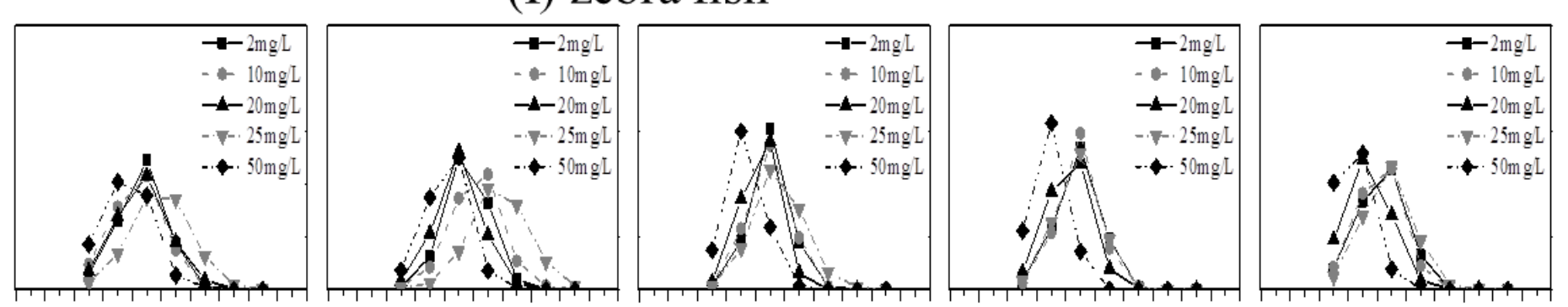

(II) red carp
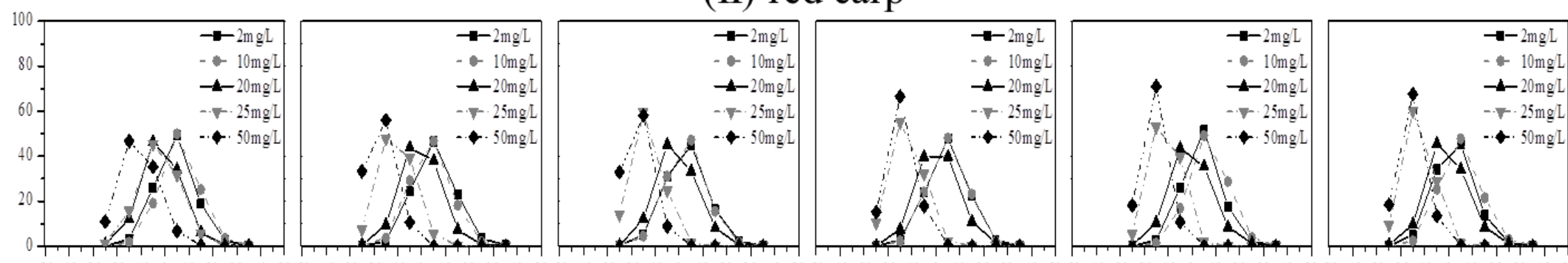

(III) Japanese medaka
(A) $31-40 \mathrm{~min}$
(B) 41-50 min
(C) 51-60 min
(D) 61-70 $\mathrm{min}$ (E) 71-80 $\mathrm{min}$
(F) $81-90 \mathrm{~min}$

Changes of swimming speed $(\triangle \mathrm{V})(\mathrm{mm} / \mathrm{s})$ 

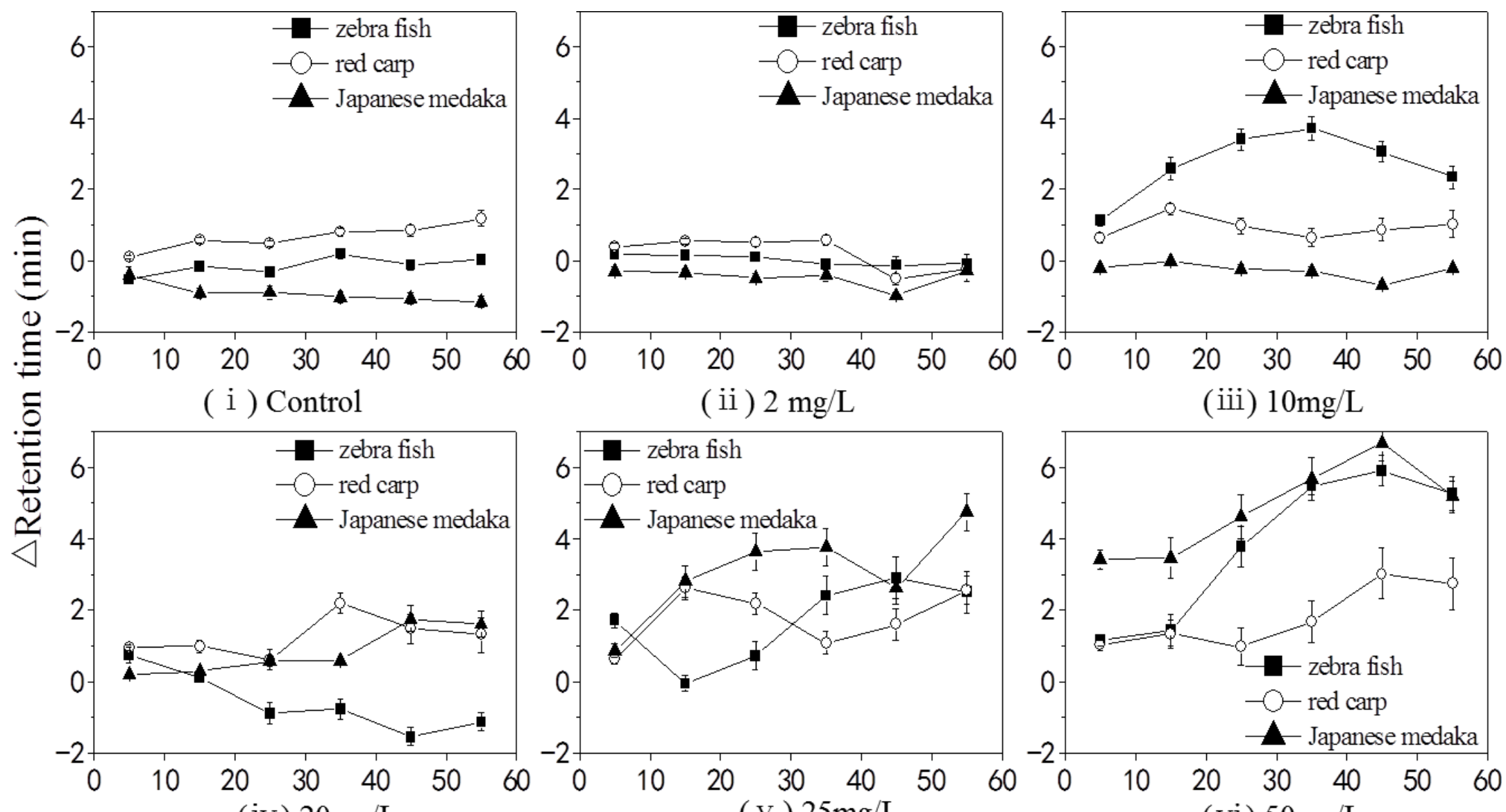

(iii) $10 \mathrm{mg} / \mathrm{L}$

(iv) $20 \mathrm{mg} / \mathrm{L}$

( v ) $25 \mathrm{mg} / \mathrm{L}$

Exposure time under SDBS (min)

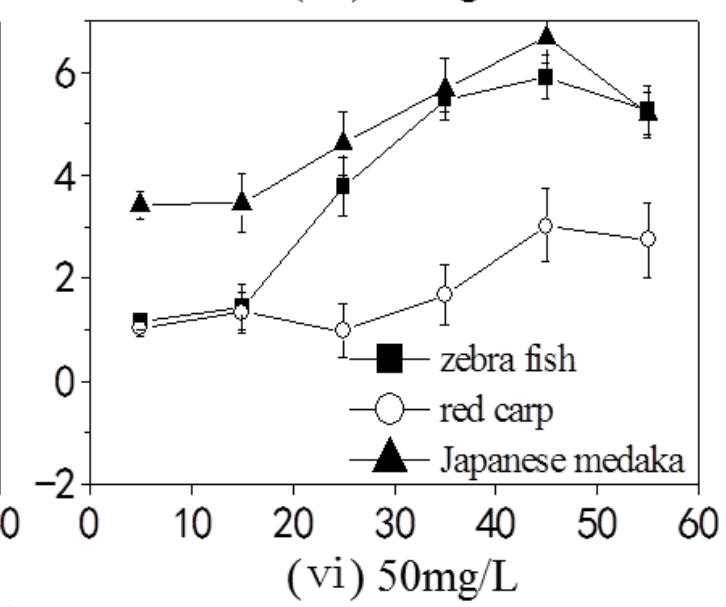

(vi) $50 \mathrm{mg} / \mathrm{L}$ 


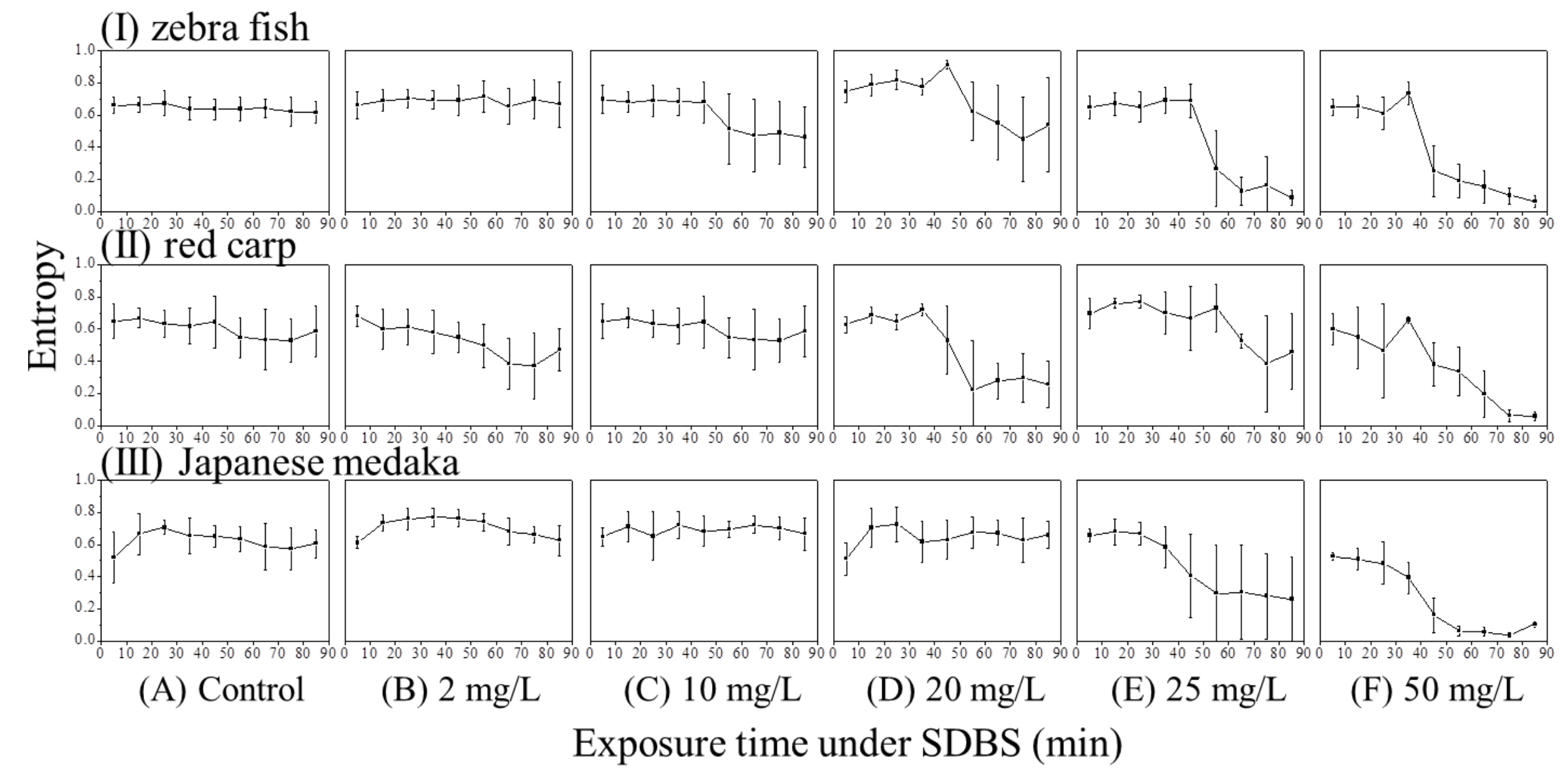


(I) zebra fish
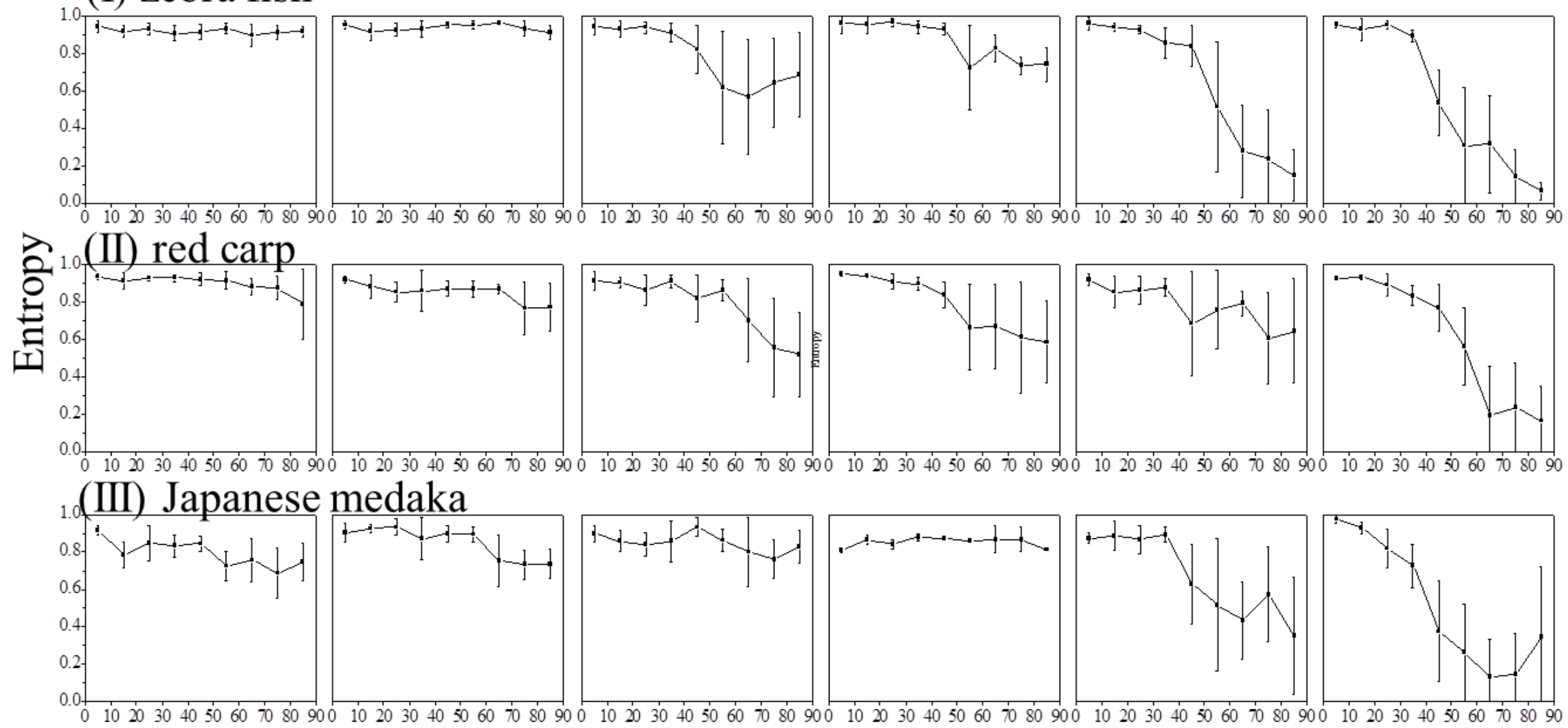
1.o(III) Japanese medaka
(A) Control
(B) $2 \mathrm{mg} / \mathrm{L}$
(C) $10 \mathrm{mg} / \mathrm{L}$
(D) $20 \mathrm{mg} / \mathrm{L}$
(E) $25 \mathrm{mg} / \mathrm{L}$
(F) $50 \mathrm{mg} / \mathrm{L}$
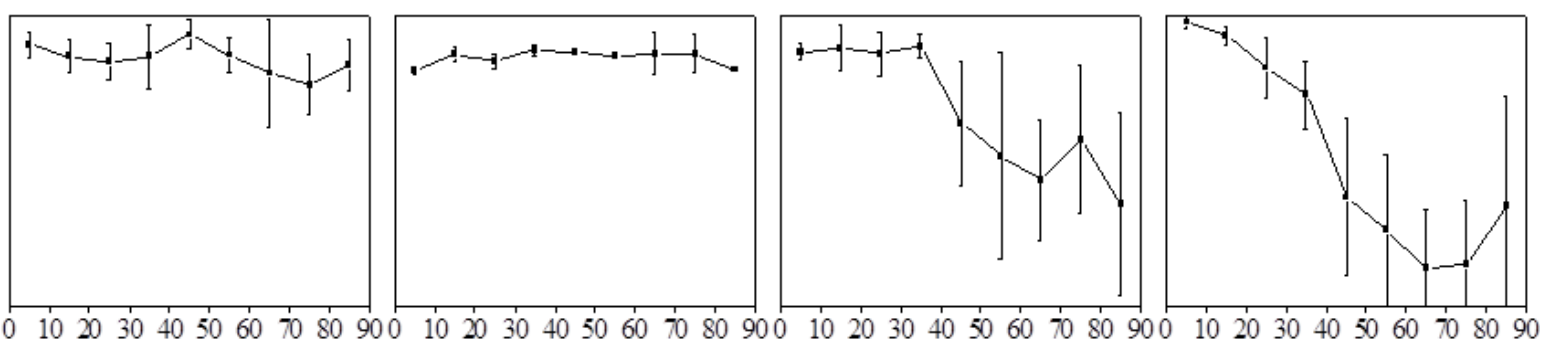
Exposure time under SDBS (min) 